\title{
Application of Neuro-Fuzzy in the Recognition of Control Chart Patterns
}

\author{
El Farissi O. \\ Laboratory LMIT, FSA, \\ BP8106 Cite Dakhla \\ Agadir, Morocco
}

\author{
Moudden A. \\ Laboratory LMIT, FSA, \\ BP8106 Cite Dakhla \\ Agadir, Morocco
}

\begin{abstract}
The control chart (CC) is an important tool in Statistical Process Control (SPC) to improve the quality of products and processes. An unnatural variation in control maps assumes that an assignable cause affects the process is present, and some actions need to be applied to solve the problem.

Thanks to their better recognition capability, NEUROFUZZY is a powerful tool for process control and rapid detection of the drifts of their evolutions.

In this paper, a NEURO-FUZZY architecture is used to recognize control charts pattern (CCPR). Several forms and architectures have been tested and the results found show that the chosen architecture leads to the best recognition quality.

\section{General Terms}

$\begin{array}{lll}\text { SPC } & = & \text { Statistical Process Control; } \\ \text { CCPR } & = & \text { Control charts pattern recognition; } \\ \text { CCP } & = & \text { Control charts pattern; } \\ \text { CC } & = & \text { Control charts; } \\ \text { NOR } & = & \text { Normal; } \\ \text { IT } & = & \text { Increasing trend; } \\ \text { US } & = & \text { Upward shift; } \\ \text { ANFIS } & = & \text { Adaptive Neuro-Fuzzy Inference System; } \\ \text { MSE } & = & \text { Mean Square Error; }\end{array}$
\end{abstract}

\section{Keywords}

Adaptive Neuro-Fuzzy Inference System (ANFIS), Statistical Process Control (SPC), Control Charts (CC), Control Charts Pattern (CCP).

\section{INTRODUCTION}

Statistical Process Control (SPC) has been widely used for monitoring the production process. Control chart pattern recognition is the most commonly SPC tools used for problem identification in processes due to special causes. Indeed, traditional Control charts use only the control limits to detect changes in the process according to the latest data sets. But the nature of the evolution of these data is not taking into account.

Otherwise the improvement of the detection quality by implementing control rules is limited by false alarms that arise by the simultaneous application of these rules.

There are three main types of patterns that commonly appear in CCP: normal (NOR), increasing trend (IT), and upward shift (US), as is shown in Figure 1.

The NOR pattern indicates that the process is operating under control. All other types of patterns are unnatural and assume that an assignable cause affecting the process is present [1].

Some researchers have used expert systems for the recognition of unnatural models $[2,3]$. The advantage of an expert system is that it contains information explicitly.

In the proposed method, an expert system was developed that has fuzzy rules obtained by an adaptive neural-fuzzy inference system (ANFIS). ANFIS represents the next generation of information processing systems. Fuzzy inference systems based on the adaptive network are good for tasks such as matching and classifying models, approximating functions, optimizing and grouping data [4-5].

This paper presents a contribution in $\mathrm{CCP}$ by using an Adaptive Neuro-Fuzzy Inference System (ANFIS) in order to improve the ability of pattern detection. The best configuration and the most accurate algorithm are retained.

The rest of the paper is organized as follow: The second section will review the literature in CCP and the use of Adaptive Neuro-Fuzzy Inference System (ANFIS) in this area. The third section will present the ANFIS design for pattern recognition. In the fourth section, the results obtained will be discussed. The last section will review the main results of the paper.

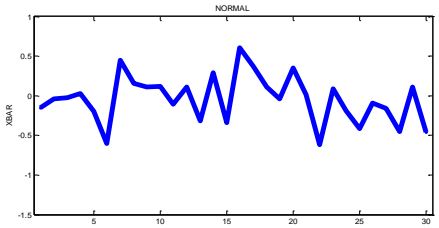

Normal (NOR)

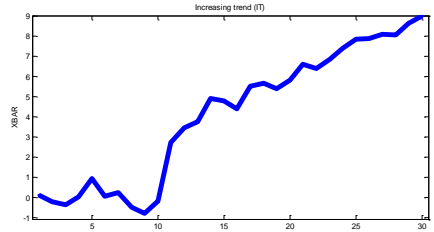

Increasing trend (IT)

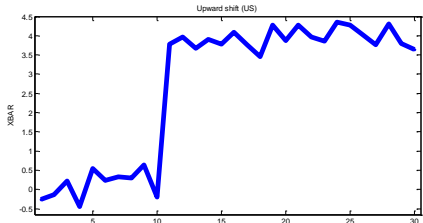

Upward shift (US)

Fig 1.Three types of basic CCPs 


\section{NEURO-FUZZY (ANFIS) FOR CONTROL CHARTS PATTERN RECOGNITION}

ANFIS can be considered as a useful approach to the neural network for solving problems of approximation of the function. Data-based procedures for the synthesis of ANFIS networks are generally based on the grouping of a set of digital samples of the unknown function to be approximated.
Since their first application, ANFIS networks have been successfully applied to classification tasks, rule-based process controls, model recognition problems and others. Here, a fuzzy inference system includes the fuzzy model [6, 7] proposed by Takagi, Sugeno and Kang to formalize a systematic approach to generating fuzzy rules from an input output data set. You can find more details about ANFIS in [89].

A basic structure of ANFIS is shown in figure 2.

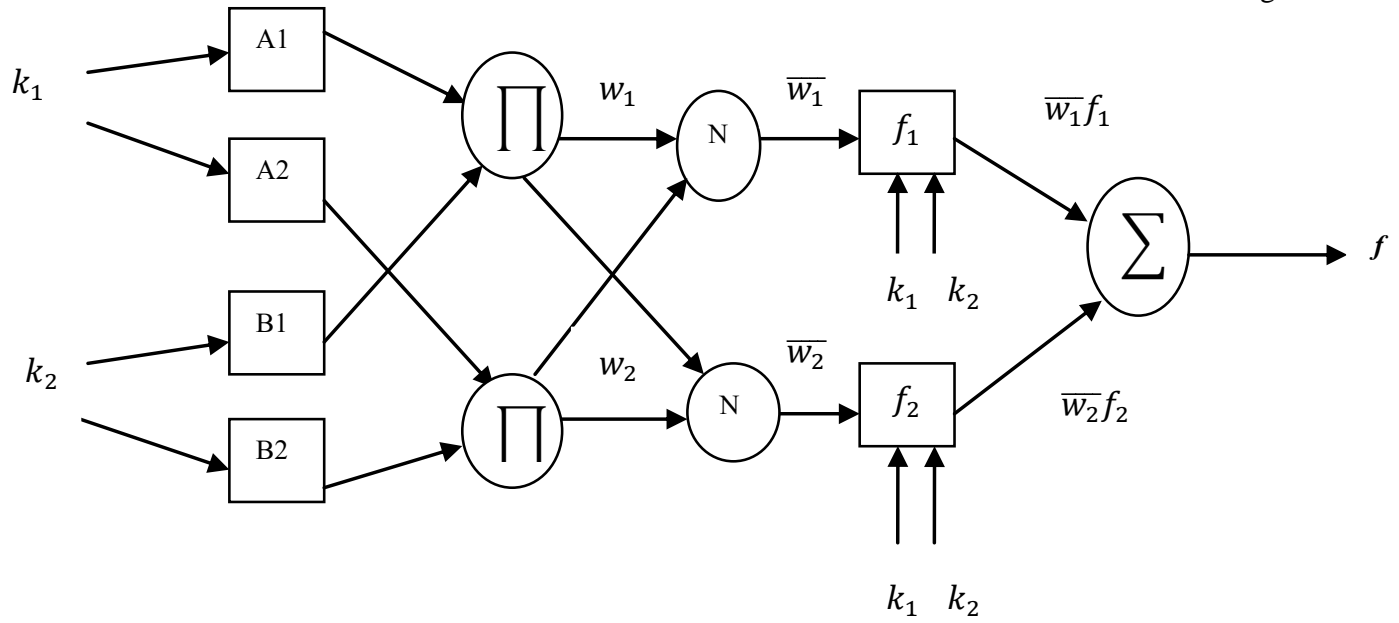

Fig 2. Basic structure of ANFIS

\section{ANFIS DESIGN FOR PATTERN RECOGNITION}

\subsection{Sample patterns}

Sample patterns to be classified are usually groups of measurements or observations coming from a real manufacturing process. Since real process containing all type of patterns is not available, simulated data are often used [10][11].The following equations, shown in Table (1), were used to generate the data points for the various patterns.

Table 1. Equations for generating various patterns

\begin{tabular}{|c|c|}
\hline Patterns & \multicolumn{2}{|c|}{ Equations } \\
\hline Normal & $\mu+\sigma * \operatorname{rand}([\mathrm{p}, \mathrm{n}])$ \\
\hline Trend increasin & $\mu+\sigma * \operatorname{rand}([\mathrm{p}, \mathrm{n}])+\mathrm{I} * \mathrm{~g}$ \\
\hline Shift up & $\mu+\sigma * \operatorname{rand}([\mathrm{p}, \mathrm{n}])+\mathrm{K} * \mathrm{~s}$ \\
\hline
\end{tabular}

where :

- $\mu$ :is the nominal mean value of the process variable;

- $\sigma$ :is the standard deviation of the process variable;

- $g$ :is the gradient of an increasing trend pattern or a decreasing trend pattern;

- $\operatorname{rand}(\mathrm{p}, \mathrm{n})$ is a Matlab Function that generates an p-by-n matrix of random normally distributed with mean $\mu=0$, variance $\sigma^{2}=1$, and standard deviation $\sigma=1$ ( $\mathrm{n}$ is the size of the observation window and $\mathrm{p}$ is the number of observations);

- $s$ :indicates the shift position in an upward shift pattern and a downward shift pattern( $\mathrm{s}=0$ before the shift and $\mathrm{s}=1$ at the shift and thereafter)

In trend and shift patterns data generation the first $\mathrm{p} / 3$ samples have a normal distribution $\left(\mathrm{K}_{\mathrm{ij}}\right.$ and $\mathrm{I}_{\mathrm{ij}}$ are set to $0)$,then after $K_{i j}=1$ and $I_{i j}=1$ :

$$
\begin{array}{llll}
\underset{p \times n}{[K]:} \quad K_{i j}=0 & \text { for } i \leq p / 3, \text { and } K_{i j}=1 & \text { for } i>p / 3 \\
\underset{p \times n}{[I]:} & I_{i j}=0 & \text { for } i \leq p / 3, \text { and } I_{i j}=i & \text { for } i>p / 3 .
\end{array}
$$

For each type of the tree CCPs, $(n * p)$ samples data were generated using the following values of parameters shown in table 2 .

\section{Table 2. Values Of Parameters Adopted To Generate} Patterns

\begin{tabular}{|c|c|}
\hline Patterns & Parameter's values \\
\hline Normal & $\mu=0, \sigma=1$ \\
\hline Increasing Trend & $\mathrm{g}=0.3$ \\
\hline Shift Up & $\mathrm{s}=4$ \\
\hline
\end{tabular}

\subsection{ANFIS design}

In this study the ANFIS design consist of use two inputs and one output as shown in figure 3. The inputs represent the statistics of the $n$ observations correspond to the sample size used for process control which are their average $\bar{X}$ and their standard deviation $S$ [12].The output with the normalized coding shown in table 3 . 
Table 3.Values Of Output Targets Related To Each Pattern

\begin{tabular}{|c|c|}
\hline Patterns & coded output $=$ Target \\
\hline Normal & 0.5 \\
\hline Increasing Trend & 0.1 \\
\hline Shift Up & 0.9 \\
\hline
\end{tabular}

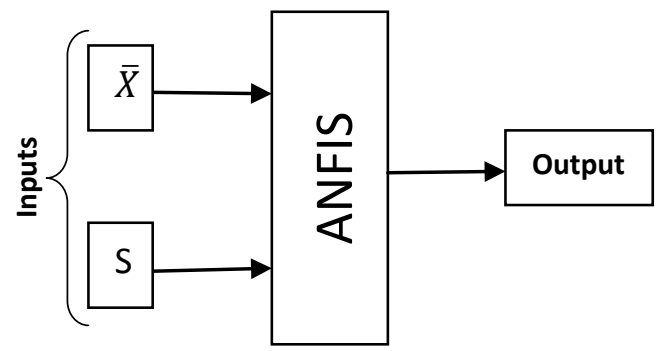

Fig 3.The structure of ANFIS used for CCPs

The training input is an (2)-by-(3xp) matrix illustrated as follow (Fig. 4).

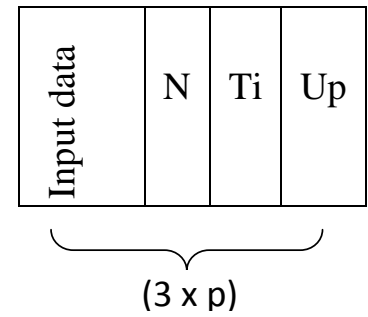

Fig 4. Training input data structure design

\subsection{Setting the Parameters of FIS Generation Methods}

We used three FIS generation approaches:

genfis1: Grid Partitioning.

genfis2: Subtractive Clustering.

genfis3: FCM.

In both the tables 4 and 5 we will found all parameters used in the execution

Table 4.Parameters for each Genfis

\begin{tabular}{|c|c|c|c|c|c|}
\hline $\begin{array}{l}\text { Genfis } \\
3\end{array}$ & Par & $\begin{array}{l}\text { Genfis } \\
2\end{array}$ & Par & $\begin{array}{l}\text { Genfis } \\
1\end{array}$ & Par \\
\hline $\begin{array}{l}\text { Number of } \\
\text { Clusters }\end{array}$ & 15 & \multirow[t]{4}{*}{$\begin{array}{l}\text { Influence } \\
\text { Radius }\end{array}$} & \multirow[t]{4}{*}{$\begin{array}{l}0.3 \\
\end{array}$} & $\begin{array}{l}\text { Number } \\
\text { of MFs }\end{array}$ & 5 \\
\hline $\begin{array}{l}\text { Partition } \\
\text { Matrix } \\
\text { Exponent }\end{array}$ & 2 & & & $\begin{array}{l}\text { Input MF } \\
\text { Type }\end{array}$ & $\begin{array}{l}\text { gaus } \\
\text { smf }\end{array}$ \\
\hline $\begin{array}{l}\text { Maximum } \\
\text { Number of } \\
\text { iterations }\end{array}$ & 200 & & & \multirow[t]{2}{*}{$\begin{array}{l}\text { Output } \\
\text { MF Type }\end{array}$} & \multirow[t]{2}{*}{$\begin{array}{l}\text { linea } \\
r\end{array}$} \\
\hline $\begin{array}{l}\text { Minimum } \\
\text { Improveme } \\
\mathrm{nt}\end{array}$ & $1^{\mathrm{e}}-5$ & & & & \\
\hline
\end{tabular}

Table 5.Parameters for all Genfis

\begin{tabular}{|l|l|}
\hline Genfis 1,2\& 3 & Parameters \\
\hline Maximum Number of Epochs & 200 \\
\hline Error Goal & 0 \\
\hline Initial Step Size & 0.01 \\
\hline Step Size Decrease Rate & 0.9 \\
\hline Step Size Increase Rate & 1.1 \\
\hline
\end{tabular}

\section{TESTS AND RESULTS}

For the network of neuron used we chose the network already developed in our article [1].

Neuro-Fuzzy Matlab's Toolbox provides a complete environment to design, train, visualize, and simulate ANFIS networks.

To develop our code we have followed the flowchart shown in the figure 5 .

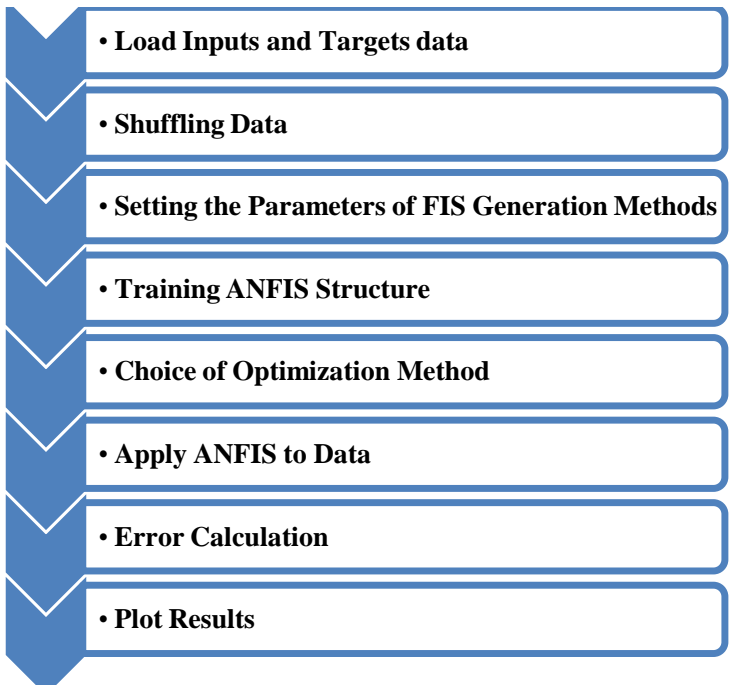

Fig 5. The flow chart of the developed code

This section presents results and comparisons of the performance between ANFIS recognizers trained and tested using three FIS generation approaches.

To determine the optimal Architecture, the coefficient of correlation $(\mathrm{R})$ between actual targets and predicted targets and the mean sum of squares of the network errors (MSE) is used [13].

$$
M S E=S S E /(n-p)(1)
$$

Where:

- $\quad S S E$ is the summed square of residuals

- $\quad n$ is the number of observations

- $\quad p$ is the number of terms currently included in the model.

Table 4 below present the comparison of MSE performance between actual targets and predicted targets for each training algorithm. 
Table 4.Comparison Of The R, MSE, Error Mean and Error St.D Performance

\begin{tabular}{|l|l|l|l|}
\hline $\begin{array}{l}\text { FIS } \\
\text { GENERATION } \\
\text { APPROCH }\end{array}$ & Genfis1 & Genfis2 & Genfis3 \\
\hline R & $99.881^{\mathrm{e}}-02$ & $99.793^{\mathrm{e}}-02$ & $99.998^{\mathrm{e}}-02$ \\
\hline MSE & $1.7235^{\mathrm{e}}-04$ & $2.9369^{\mathrm{e}}-04$ & $2.8933^{\mathrm{e}-} 06$ \\
\hline Error Mean & $-1.5408^{\mathrm{e}}-03$ & $2.7661^{\mathrm{e}}-04$ & $8.5307^{\mathrm{e}}-05$ \\
\hline Error St.D & $1.3068^{\mathrm{e}}-02$ & $1.7175^{\mathrm{e}}-02$ & $1.7028^{\mathrm{e}}-03$ \\
\hline
\end{tabular}

Table 4 show the lowest MSE and the best R are obtained for Genfis3 (FCM).

In figure 6 , the predicted target is practically identical with the actual target.

The implementation shows that the ANFIS architecture chosen gives the best performance sought (In figure 7:R close to 1

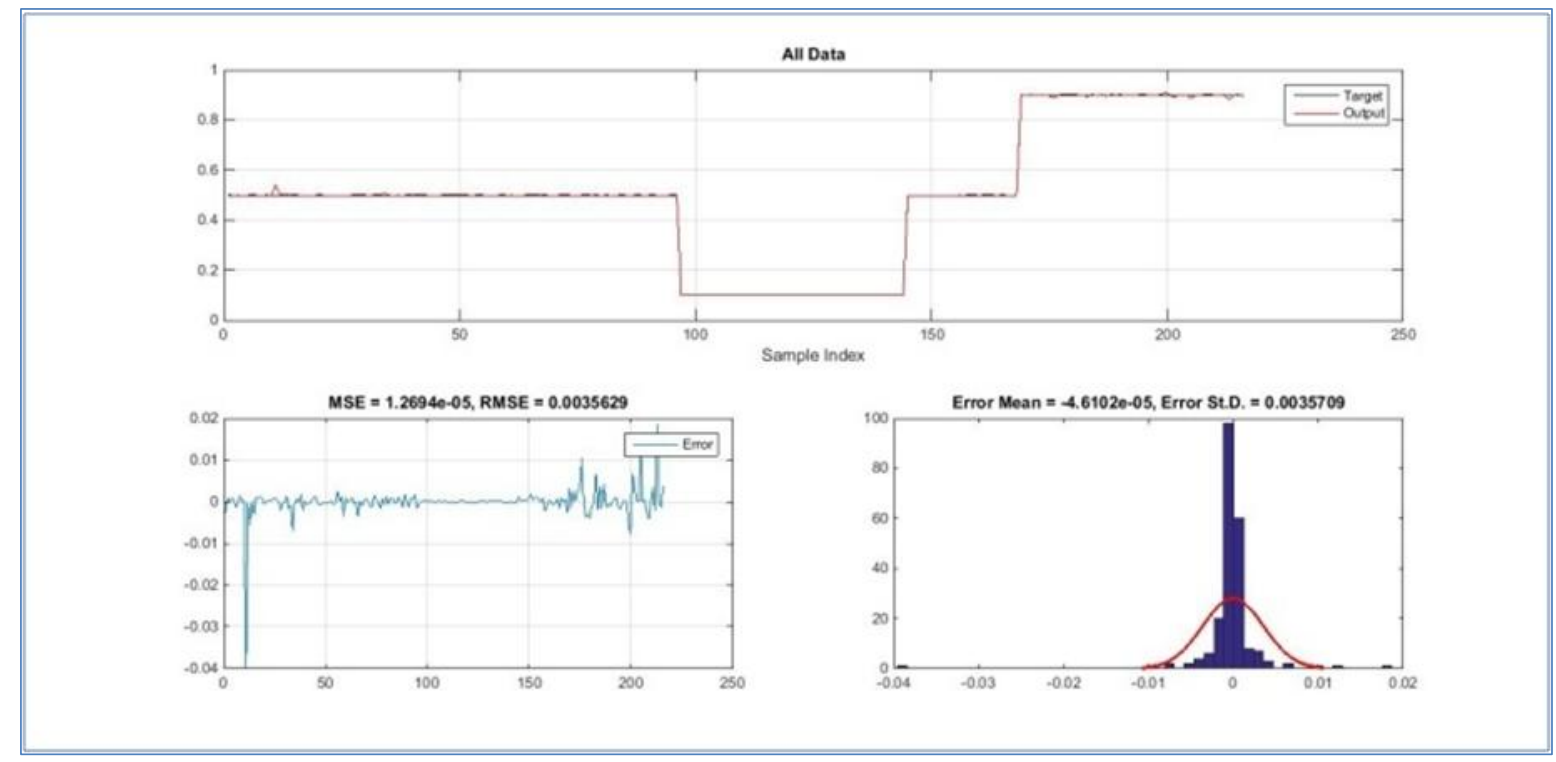

Fig 6. Comparison between actual targets and predicted targets
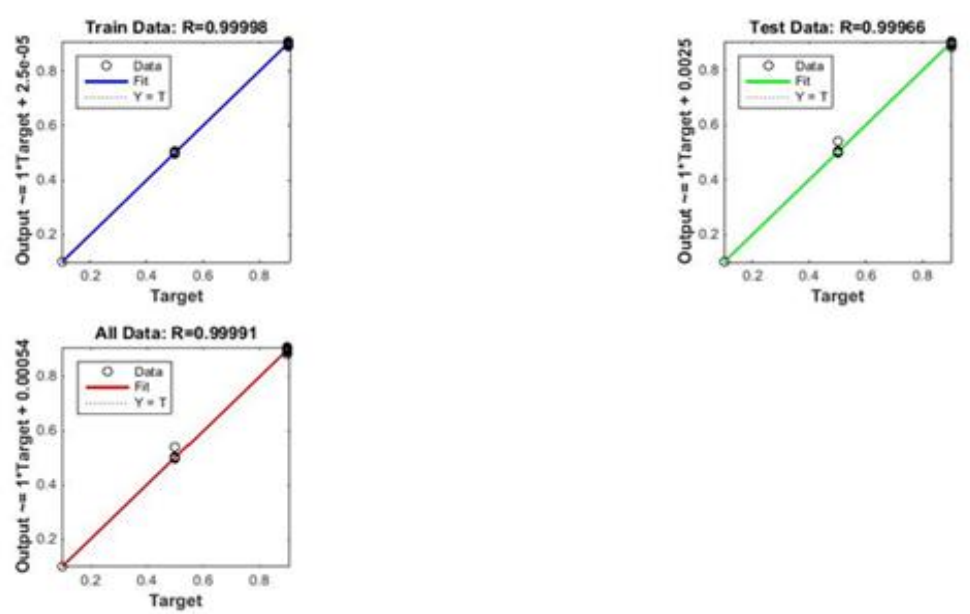

Fig 7. Comparison between actual targets and predicted targets 


\section{CONCLUSION}

In this paper, the objective was to improve the quality of the Neuro-Fuzzy especially Adaptive Neuro-Fuzzy Inference System ANFIS in CCP recognition. To evaluate its relative performance. The results show that the ANFIS architecture chosen gives the best performance in patterns recognition problems.

The work will be extended to study other patterns namely: Decreasing trend (DT), Downward shift (DS) and cyclic (CYC) taking into account other criteria such as the number of iterations.

\section{REFERENCES}

[1] O.El Farissi \& all. Using Artificial Neural Networks for Recognition of Control Chart Pattern.International Journal of Computer Applications (0975 - 8887) Volume 116 - No. 3, April 2015

[2] J.A. Swift,J.H. Mize. Out-of-control pattern recognition and analysis for quality control charts using lisp-based systems. Computers and Industrial Engineering 1995; 28: 81-91.

[3] J.R. Evans, W.M. Lindsay. A framework for expert system development in statistical quality control. Computers and Industrial Engineering 1998; 14: 335343.

[4] S. Narayanamoorthy, S.Saranya, S.Maheswari. A Method for Solving Fuzzy Transportation Problem (FTP) using Fuzzy Russell's Method. International Journal of Intelligent Systems and Applications (IJISA). PP.71-75, Pub. Date: 2013-1-3.

[5] M. Hosoz, H.M. Ertunc, H. Bulgurcu. An adaptive neuro-fuzzy inference system model for predicting the performance of a refrigeration system with a cooling tower. Expert Systems with Applications 2011; 38: 14148-14155.

[6] M. Sugeno, G.T. Kang, Structure identification of fuzzy model, Fuzzy Sets Syst. 28 (1988) 15-33.

[7] T. Takagi, M. Sugeno, Fuzzy identification of systems and its applica-tions to modeling and control, IEEE Trns. Syst., Man Cybern 15 (1985) 116-132.
[8] J. Kennedy, R. Eberhart, Particle swarm optimization, in: Proceedings of IEEE International Conference on Neural Networks 4 (1995) 1942-1948.

[9] A. Zeki, M. S. Zakaria. New primitive to reduce the effect of noise for handwritten features extraction. IEEE 2000 Tencon Proceedings: In-telligent Systems and Technologies for the NewMillennium, (2000) 24-27.

[10] N.V.N. IndraKiran,M.Pramiladevi and G.Vijaya Lakshmi, Training Multilayered Perceptrons for Pattern Recognition: A Comparative Study of Five Training Algorithms, IMECS, Vol. I, March 2011.

[11] B. M.Wilamowski, Neural Network Architectures. Industrial Electronics Handbook (vol. 5 - Intelligent Systems, 2nd Edition, chapter 6, pp. 6-1 to 6-17, CRC Press, 2011).

[12] A. E .Smith, X-bar and R control chart interpretation using neural computing, International Journal of Production Research, 32(2), 309-320, 1994.

[13] S. Makridakis, and M. Hibon, Evaluating Accuracy (or Error) Measures, Working Paper, INSEAD, Fontainebleau, France, 1995

\section{AUTHOR PROFILE}

${ }^{1}$ Omar El farissi was born in 1972 in Morocco.Hereceived his MASTER in Laboratory of Mechanics, precedesof energy and environments(LMP2E), of ENSA-Agadir in 2012. In $2012 \mathrm{He}$ joined the Laboratory of Metrology and information's treatment (LMIT) of the FSAIbn Zohr University, Agadir, Morocco. His current research field is SPC and her industrial applications.

${ }^{2}$ Pr Ali Moudden was born in 1958 in Morocco. He obtained (1987) the " doctorat d'état" in physics at the University of Caen (France). He founded with other colleagues in 1991, the laboratory of instrumentation and measurements at the Faculty of Sciences of Agadir (Morocco), that became in 2005 the laboratory of metrology and information processing. Laboratory activities are focused mainly on the development of purely physical techniques for evaluation of materials and monitoring of processes. He was director of higher school of technology of Agadir during the period 2005 2011. 